Contents available at: Sri Lanka Journals Online

\title{
Rainfall Trends in the North-Western and Eastern Coastal Lines of Sri Lanka Using Non - Parametric Analysis
}

\author{
W.W.U.I. Wickramaarachchi ${ }^{*}$, T.U.S. Peiris ${ }^{2}$ and S. Samita ${ }^{1,3}$ \\ ${ }_{1}^{1}$ Postgraduate Institute of Agriculture, University of Peradeniya, Peradeniya, Sri Lanka \\ 2 Biostatistics Unit, Faculty of Livestock, Fisheries and Nutrition, Wayamba University, Makandura, Gonawila, Sri Lanka \\ ${ }^{3}$ Department of Crop Science, Faculty of Agriculture, University of Peradeniya, Peradeniya, Sri Lanka
}

\section{ARTICLE INFO}

\section{Article history:}

Received: 12 July 2019

Accepted: 23 September 2019

Available online: 1 April 2020

\section{Keywords:}

Climate change

Coastal line

Non -parametric tests

Rainfall

Trend analysis

\section{Citation:}

Wickramaarachchi, W.W.U.I., Peiris, T.U.S. and Samita, S. (2020). Rainfall Trends in the North-Western and Eastern Coastal Lines of Sri Lanka Using Non-Parametric Analysis. Tropical Agricultural Research, 31(2): 41-54.

DOI: http://doi.org/10.4038/tar.v31i2.8366

Wickramaarachchi, W.W.U.I. https://orcid.org/0000-0002-6697-2246

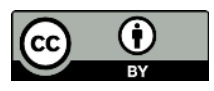

\begin{abstract}
The changes in the global rainfall have raised concerns over the present and possible future use of coastal areas in many Asian countries including Sri Lanka. However, no in-depth analysis of rainfall of these coastal lines of Sri Lanka has been performed yet to understand any changes in the pattern in general. This study was carried out to fulfil the above need, especially focusing on rainfall of North-Western and Eastern coastal lines of Sri Lanka. The rainfall data for a period of 30 years (1986-2016) were used in the study and analysis was performed using the tests, Mann Kendall, Sen's slope estimator, and sequential Mann Kendall. Mann-Kendall's test indicated positive trend in annual rainfall of most parts of North-Western coastal line but negative monotonic decrease at 4 stations, namely, Chilaw, Horakele, Lunuwila and Palaviya. In the Eastern coastal line, significant positive trend in annual rainfall was observed at 4 stations, namely, Kantale, Batticaloa, Pottuvil and Mylambaveli. The monthly rainfall analysis of North-Western coastal line revealed significant positive trends at Kottukachchiya and Anamaduwa stations in March and December respectively and in the Eastern costal line, positive trends were observed at Kantalae, Mylambaveli and Navatkiri Aru for February. The stations except Anamaduwa in NorthWestern coastal line recorded a significant negative trend in rainfall in the month of May. No station showed a significant positive trend during Southwest Monsoon season. During the Northeast Monsoon season, all the nineteen stations showed an increase in rainfall amounts while two locations in NorthWestern region and six locations in Eastern showed a significant upward trend. With these dynamic rainfall trends, it can be reiterated that it is vital to advocate climate mitigating actions to reduce impacts of changes in rainfall trends.
\end{abstract}

*Corresponding author: upzwickramaarachchi@gmail.com 


\section{INTRODUCTION}

The impact of climate change and climate variability on human life and environment have steered the scientific community to monitor the behaviour of weather and climate variables. The Inter-Governmental Panel on Climate Change (IPCC) defines climate change as a change in the state of the climate that can be identified (e.g. using statistical tests) by changes in the mean and/or the variability of its properties and that persists for an extended period, typically decades or longer (Solomon et al., 2007).

Climate variability involves changes in precipitation and atmospheric temperature, slower winds, and acidification of the ocean (Khaniya et al., 2019). However, temperature and rainfall are very important factors influencing climate variability and extremes. Between these two, changes in rainfall is one of the most important factors, which impact the society and then determine the overall impact of climate change (Bhuyan et al., 2018). Rainfall variations have consequences on water resources, agriculture, forestry, irrigation schedules, fishery and aquaculture industry (Abdi et al., 2017). Also, changes of the amount, pattern, and intensity of rainfall may lead to extraordinary weather, which is more severe in some parts of the earth (Zamani et al., 2018). The fourth assessment report (AR4) of IPCC (2007) indicated that the low-lying coastal areas in many Asian countries including Sri Lanka are facing challenges associated with changes of the climate.

The changes in the global rainfall pattern have raised concerns of its impact on the future. For instance, analysis of trends in rainfall in Australia (Chowdhury et al., 2015), New York of USA (Da Silva, 2004) and Mexico from 1920 to 2004 (González et al., 2008) have indicated a positive trend. Negative trends have been detected in Sicily (Italy) by Cannarozzo et al. (2006) and in India (Mondal et al., 2015). Other work in Asian countries include rainfall trend analysis in India (Sukrutha et al., 2017), trend analysis for both temperature and rainfall in India (Mondal et al., 2015), and for North-western region of Bangladesh (Bhuyan et al., 2018).
Where rainfall trends in Sri Lanka is concerned, previous investigations have demonstrated significant trends (Ratnayake and Herath, 2005; Jayawardene et al., 2005; Burt and Weerasinghe, 2014; Karunathilaka et al., 2017). For instance, the trends in rainfall extremes in Sri Lanka have shown that Colombo had experienced the highest increase of rainfall $(3.15 \mathrm{~mm} /$ year) whereas two other cities Kandy and Nuwara Eliya had an annual decrease of 2.88 and $4.87 \mathrm{~mm} /$ year respectively in 2010 (Jayawardene et al., 2015). Malmgren et al., (2003), Ranatunge et al., (2003), Ampitiyawatta and Guo (2010), and Wickramagamage (2016) have shown rainfall trends in many other important areas in Sri Lanka. Recently, Khaniya et al. (2019) analyzed the rainfall trend of Uma Oya catchment and showed significant positive trends in three rainfall gauges; Kirklees Estate, Ledgerwatte Estate and Welimada, only in the first intermediate period (March-April). The effect of delayed southwest monsoon to Sri Lanka was found by Naveendrakumar et al. (2018) indicating a significant decrease of wet days in May at $15 \%$ of the 32 considered gauge stations within the country. Munasinghe et al. (2010) reported weather related hazards due to the irregular seasonal changes (Ministry of Disaster Management, 2014) on shrimp farming in Puttlam.

The North-western and Eastern coastal line can be considered as a hub of many industries like shrimp farming, coconut plantations and fisheries in Sri Lanka with substantial contribution towards socio-economic development in terms of income and employment in North-western and Eastern Coasts of the country. Changes in global temperatures, shifting rainfall patterns, rising sea levels and increasing frequency of extreme climate events such as floods, cyclones and droughts can create an adverse impact on these industries. Therefore, exploration of the applicability of statistical methods is urgently needed to reveal the changes to mitigate the effects of climate changes in these regions.

Trend analysis has been one of the most popular statistical approaches used by researchers for analysing the variation of 
hydro-meteorological variables during the last two decades. Rather than fitting parametric models to describe trends in time series such as studies on rainfall and temperature trends in Sri Lanka (Zubair et al., 2005; De Costa, 2010), non-parametric methods are more appropriate to detect annual, monthly and seasonal rainfall trends due to a number of reasons (Xu et al., 2007). The non-parametric methods are not sensitive to outliers and can be applied for nonnormally distributed series with missing values (Ahmadi et al., 2018). Among the nonparametric methods, the Mann-Kendall (MK) test, which was proposed by Mann (1945) and Kendall (1975), is more popular and has been suggested by World Meteorological Organization (WMO) for analysing the trends of hydro-meteorological time series (Kumar et al., 2009).

In the Sri Lankan perspective, although MK trend analysis were previously used by Herath and Rathnayake (2005), Jayawardene et al. (2005) and Karunathilaka et al. (2017), seasonality components have not been appropriately addressed for the detection of long-term trends (Naveendrakumar et al., 2018) and identification of trend locations to detect change points. Hence, this study was undertaken to fill the above gap, and specifically to detect potential trends and assess their significance.

\section{MATERIALS AND METHODS}

\section{Data and Study Area}

Monthly rainfall values from 19 meteorological and agro-meteorological stations representing the Eastern (Allai tank ${ }^{1}$, Ampara $^{2}$, Batticaloa ${ }^{3}$, Kallar ${ }^{4}$ Kantale ${ }^{5}$, Mylambaveli ${ }^{6}$, Navakiri Aru ${ }^{7}$, Palampoddaru ${ }^{8}$, Pottuvil $^{9}$, Sagamam Kulam ${ }^{10}$, Trincomalee ${ }^{11}$ ) and North-Western (Anamaduwa ${ }^{12}$, Chilaw ${ }^{13}$, Horakele $^{14}$, Karukkuwa ${ }^{15}$, Kottukachchiya ${ }^{16}$, Lunuwila17, Palaviya18, Puttlam ${ }^{19}$ ) provinces (Plate 1) for the period of 1986-2016 were used in this study. The monthly rainfall data were used to compute the annual and seasonal (first Inter-monsoon (March \& April), Southwest Monsoon (May-September), second Inter-monsoon (October \& November) and North-east Monsoon (January, February)) time series. Trend analysis of the rainfall data was carried out on the basis of annual, seasonal and monthly basis.

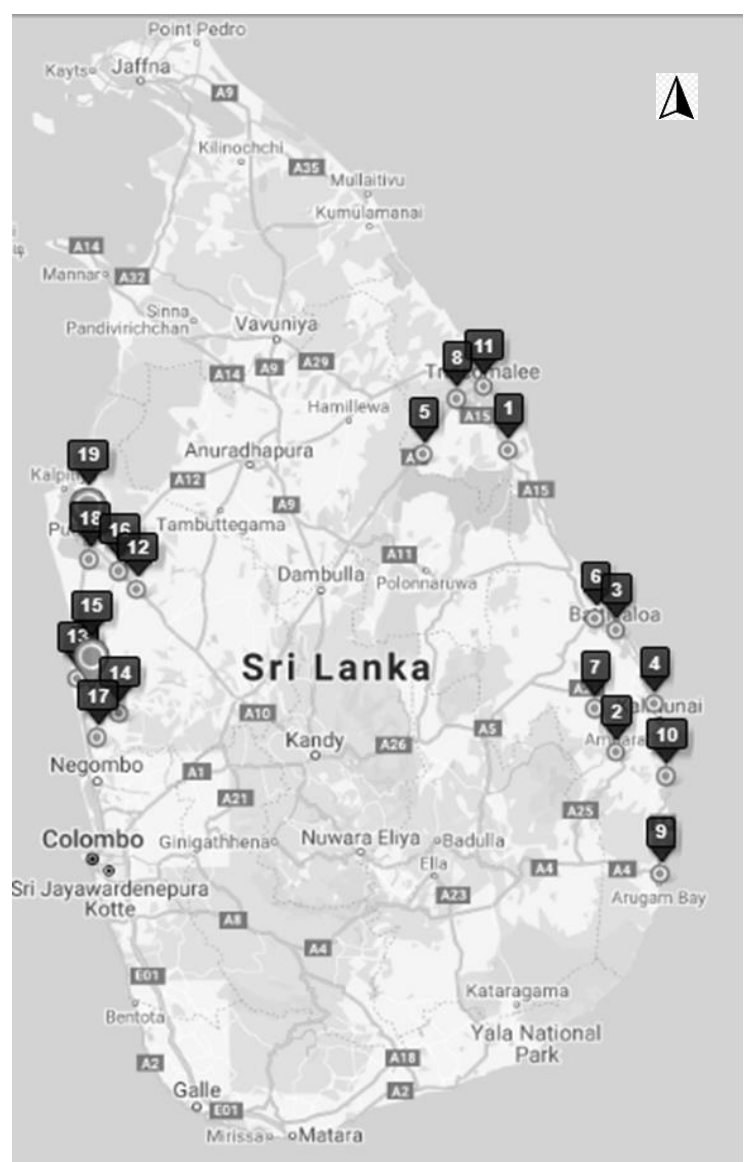

Plate 1: Distributions of precipitation stations used in the study.

\section{Serial dependency check and removal}

Autocorrelation or serial dependency within a time series data is always considered as one of the main problems of time series data analysis and trend detection. Non-parametric trend tests such as Mann-Kendall (MK) gives incorrect or too large rejection rates when applied to an autocorrelated time series data. Since the variance of the MK test statistic increases with the magnitude of serial correlation, positive serial correlation increases the Type I error when the time series has no trend (Yue et al., 2002). Hence, the serial-correlation test was applied to the data series (Yue and Wang, 2004) to observe the presence of any serial dependency in the series. 


\section{Detection of trend and magnitude}

To test the long-term rainfall trend, especially for monotonic trend analysis, Mann-Kendall test was applied. It is a nonparametric rank-based procedure, robust to the influence of extremes and suitable for application with skewed variables (Hamed, 2008). More particularly, this technique can be adopted in cases with non-normally distributed data, data containing outliers and non-linear trends (Birsan et al., 2005). According to this test, the null hypothesis $\mathrm{H}_{0}$ indicates that the deseasonalised data $\left(\mathrm{x}_{1}, \ldots\right.$, $\mathrm{x}_{\mathrm{n}}$ ) is a sample of $\mathrm{n}$ independent and identically distributed random variables (Hirsch et al., 1982). The alternative hypothesis $\mathrm{H}_{1}$ of a two-sided test is that the distributions of $\mathrm{x}_{\mathrm{k}}$ and $\mathrm{x}_{\mathrm{j}}$ are not identical for all $\mathrm{k}, \mathrm{j} \leq \mathrm{n}$ with $\mathrm{k} \neq \mathrm{j}$. The test statistic $\mathrm{S}$, which has mean zero and a variance computed by Equation (3), is calculated using Equations (1) and (2), and is asymptotically normal (Hirsch et al., 1982):

$$
S=\sum_{k=1}^{n-1} \sum_{j=k+1}^{n} \operatorname{sgn}\left(X_{j}-X_{k}\right)
$$

where $\operatorname{sgn}\left(X_{j}-X_{k}\right)$ is the signum function (the derivative of the absolute value function). The $\mathrm{S}$ statistic, in cases where the sample size $\mathrm{n}$ is larger than 10 , is assumed to be asymptotically normal, with $\mathrm{E}(\mathrm{S})=0$ and

$$
\operatorname{Var}(S)=\left[n(n-1)(2 n+5)-\sum_{t} t(t-1)(2 t+5)\right] / 18
$$

where $t$ refers to the extent of any given tie and $\Sigma$ t states the summation over all ties. The standard normal variate $\mathrm{Z}$ is computed by Equation 2 (Partal and Kahya 2006).

$Z= \begin{cases}\frac{S-1}{\sqrt{\operatorname{var}(S)}} & \text { if } S>0 \\ 0 & \text { if } S=0 \\ \frac{S+1}{\sqrt{\operatorname{Var}(S)}} & \text { if } S<0\end{cases}$

Therefore, in case $|\mathrm{Z}| \leq \mathrm{Z} 1-\alpha / 2$ in a two-sided test for trend, the null hypothesis $\mathrm{H}_{0}$ should be accepted at the $\alpha$ level of significance. A positive value of $S$ predicts an "upward trend", while a negative value of $S$ indicates a "downward trend". Trend magnitude was determined by the Theil-Sen's estimator (Theil, 1950; Sen, 1968). These methods are widely used and are proven to be better for hydrological and meteorological trend detection (Tabari and Marofi, 2010). The slope estimates $Q_{i}$ of $N$ pairs of data are calculated as $Q_{i}=\left(x_{j}-x_{k}\right) /(j-k)$ for $i=1, \ldots, N$ where $x_{j}$ and $x_{k}$ are data values at times $j$ and $k(j>k)$ respectively. The Sen's estimator of slope derives from the above $\mathrm{N}$ values of $\mathrm{Q}_{\mathrm{i}}$ and equals to their median. When there is only one datum in each time period, then $\mathrm{N}=$ $n(n-1) / 2$, where $n$ corresponds to the number of time periods. The $\mathrm{N}$ values of slopes are ranked from the smallest to largest and if $\mathrm{N}$ is odd, Sen's estimator of slope is calculated as $\mathrm{Q}_{\text {median }}=\mathrm{Q}_{(\mathrm{N}+1)} / 2$. On the other hand, in case that $\mathrm{N}$ is even, the estimator arises from $\mathrm{Q}_{\text {median }}=\left[\mathrm{Q}_{\mathrm{N} / 2}+\right.$ $\left.\mathrm{Q}_{(\mathrm{N}+2) / 2}\right] / 2$ giving Sen's estimator.

\section{Sequential Mann-Kendall analysis}

Mann-Kendall method does not provide information about the complete structure of the trend (trend picture) for the whole time series at the end of any time. There may be fluctuation points or changes in the trend location over the considered period of time series which can be identified by applying the test sequentially for every individual period (Sneyers, 1990). In this method, Sequential values $u(t)$ (prograde series) and $u^{\prime}(t)$ (retrograde series) from the progressive analysis of the MK test were determined in order to see change of trend with time (Sneyers, 1990). Herein, $\mathrm{u}(\mathrm{t})$ is a standardized variable that has zero mean and unit standard deviation. Therefore, its sequential behavior fluctuates around the zero level. $u(t)$ is the same as the $\mathrm{z}$ values that are found from the first to last data point. This test considers the relative values of all terms in the time series $\left(\mathrm{x}_{1}, \mathrm{x}_{2}, \ldots, \mathrm{x}_{\mathrm{n}}\right)$. The following steps are applied in sequence:

1. The magnitudes of $x j$ annual mean time series, $(j=1, \ldots, n)$ are compared with $X_{k}$, $(\mathrm{k}=1, \ldots, \mathrm{j}-1)$. At each comparison, the number of cases $x_{j}>x_{k}$ is counted and denoted by $n_{j}$.

2. The test statistic $t$ is then given by equation;

$$
t_{j}=\sum_{1}^{j} n_{j}
$$


3. The mean and variance of the test statistic

$$
\begin{aligned}
& \text { are } \quad E(t)=\frac{n(n-1)}{4} \quad \text { and } \\
& \operatorname{Var}\left(t_{j}\right)=[j(j-1)(2 j+5)] / 72
\end{aligned}
$$

4. The sequential values of the statistic $u(t)$ are then calculated as

$$
u(t)=\frac{t_{j}-E(t)}{\sqrt{\operatorname{Var}\left(t_{j}\right)}}
$$

Similarly, the values of $\mathrm{u}^{\prime}(\mathrm{t})$ are computed backwards, starting from the end of the series. The method has been used by many researchers to detect the starting point of trends (Makokha and Shisanya, 2010) and to perceive the trend turning points (Rahman et al., 2017).

\section{RESULTS AND DISCUSSION}

Initially, the serial correlation test was performed to all time series in order to check the randomness of the data (Modarres and Da Silva, 2007). It was found that the individual monthly data sets of every station were free from autocorrelation at $\alpha=0.05$. Hence, Mann-Kendall trend test was applied to annual, monthly and seasonal rainfall time series directly to detect trends at each of the time scales for the selected 19 stations in North-western and Eastern coastal line.

\section{Trends of annual rainfall data}

The annual rainfall data showed an upward trend for most parts of the North-western and Eastern coastal lines while four stations Chilaw, Horakele, Lunuwila and Palaviyaya in North-western province showed a downward annual trend indicating a monotonic decrease in annual rainfall in these stations. Kantale, Batticaloa, Pottuvil and Mylambaveli in Eastern coastal line showed a significant upward trend at $95 \%$ confidence (Table 1).

Table 1: Details of the Mann-Kendall trend analysis for annual rainfall data

\begin{tabular}{lcccc}
\hline Station & $\begin{array}{c}\text { MK statistics } \\
\text { (S) }\end{array}$ & $\begin{array}{c}\text { Kendall's } \\
\text { tau }\end{array}$ & p-value & Sen's slope \\
\hline North-western coastal line & & & & \\
Anamaduwa & 101 & 0.217 & 0.086 & 10.6 \\
Chilaw & -89 & -0.191 & 0.13 & -12.4 \\
Horakele & -55 & -0.118 & 0.35 & -5.0 \\
Karukkuwa & 17 & 0.037 & 0.773 & 2.0 \\
Kottukachchiya & 93 & 0.196 & 0.122 & 8.9 \\
Lunuwila & -5 & -0.011 & 0.932 & -0.5 \\
Palaviya & -11 & -0.032 & 0.799 & -1.1 \\
Puttlam & 3 & 0.006 & 0.959 & 0.4 \\
Eastern coastal line & & & & \\
Allai tank & 67 & 0.154 & 0.232 & 10.2 \\
Kallar & 87 & 0.205 & 0.112 & 12.8 \\
Kantale & $171^{*}$ & 0.393 & 0.002 & 22.6 \\
Palampoddaru & 117 & 0.186 & 0.148 & 26.1 \\
Ampara & 69 & 0.205 & 0.112 & 13.6 \\
Batticaloa & $131^{*}$ & 0.301 & 0.019 & 22.3 \\
Trincomalee & 93 & 0.214 & 0.097 & 13.5 \\
Pottuvil & $125^{*}$ & 0.292 & 0.023 & 17.8 \\
Mylambaveli & $165^{*}$ & 0.375 & 0.004 & 21.6 \\
Navakiri Aru & 25 & 0.057 & 0.656 & 3.6 \\
Sagamam Kulam & 23 & 0.044 & 0.735 & 4.1 \\
\hline *statistically significantat P-values0.05 & & & &
\end{tabular}

*statistically significant at P-value $\leq 0.05$ 
Sen's estimator of slope in significant locations ranged from 17.8-22.6 mm/year. In fact, similar results have been obtained by Karunathilaka et al. (2017) for the stations Chilaw, Batticaloa and Pottuvil. The remaining stations did not show any significant annual trend. The Kanatale station showed the maximum positive trend in annual precipitation series (22.6 mm/year) across study stations from 1986 to 2016.

The results of Sequential Mann-Kendall test statistics for annual total rainfall data set of Eastern coasts clearly detected change points (Figure 1) with an increasing trend. Most significant change point in annual rainfall totals over the period from 1986-2016 was recorded at Kantale in 1990 . The $\mathrm{u}(\mathrm{t})$ statistics depicted that, after a change in 1990, annual rainfall in Kantale leaned towards an

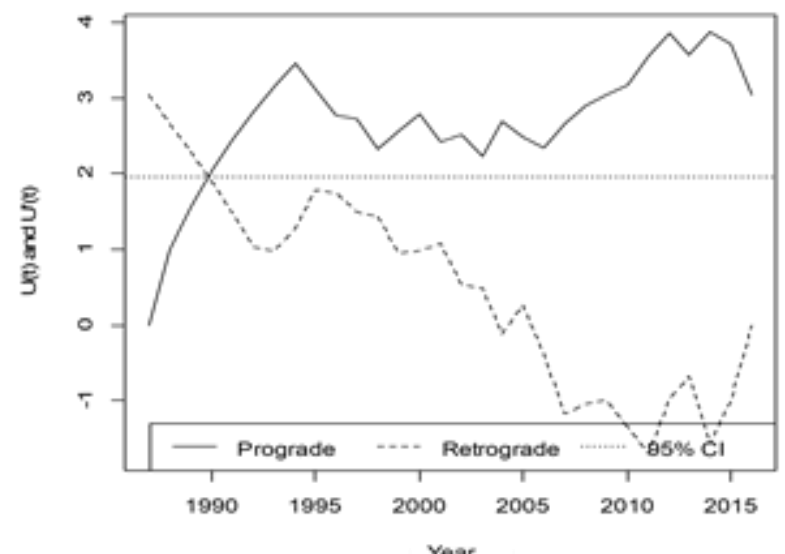

(a)

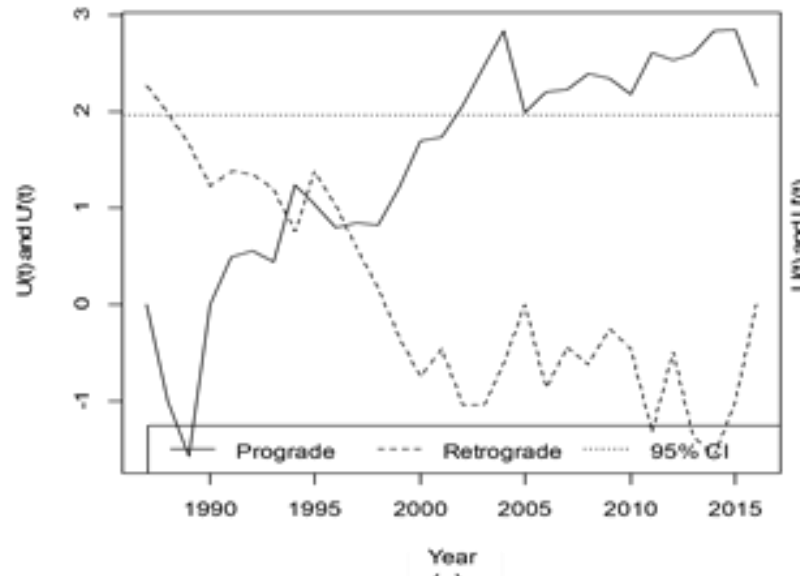

(c) increasing trend with increased rainfall events (Figure 1-a). The $u(t)$ and $u^{\prime}(t)$ plots of Batticaloa, Pottuvil and Malymbavli intersect each other for several times during the period of 1993 to 2000 signifying no recognizable trend in the series. In locations Pottuvil and Mylambaveli after the change point in 1999, the curves diverge, and prograde $u(t)$ series shows an upward trend. All of these stations recorded heavy rainfall occurrences for the considered time period at $95 \%$ confidence interval. In fact, this increase in rainfall of was more or less similar to the findings of Karunathilaka et al. (2017) for rain gauge stations at Batticaloa and Pottuvil. However, a previous study using a century-long dataset reported that the annual rainfall calculated using monthly averages did not show consistent increases or decreases in Sri Lanka (Jayawardene et al., 2005).

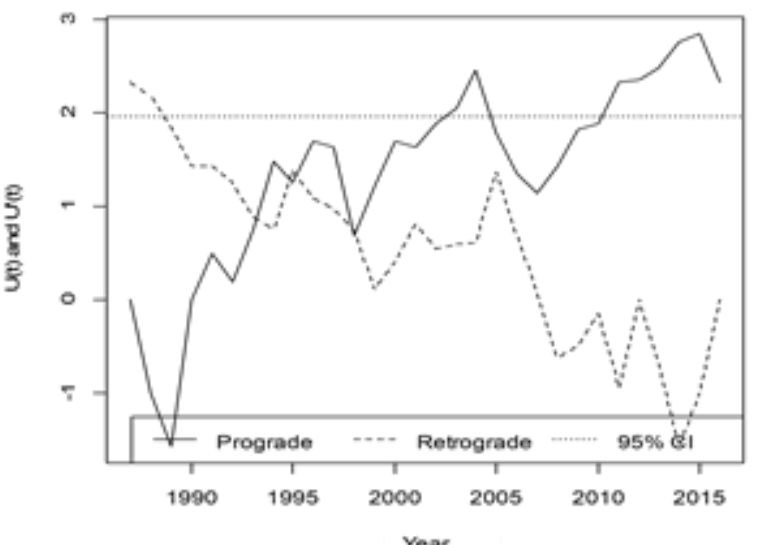

(b)

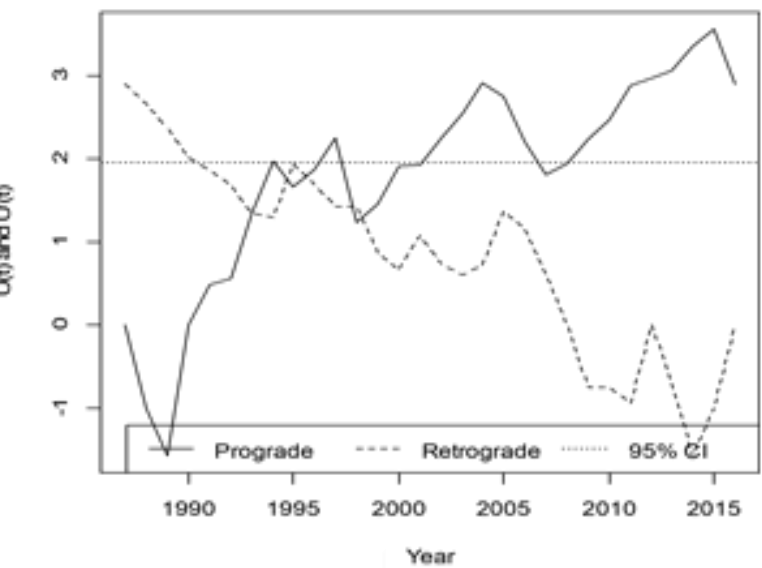

(d)

Figure 1: Graphical representation of annual sequential values of the statistics prograde series $u(t)$ (solid line) and retrograde series $u^{\prime}(t)$ (dashed line) obtained by SQ-MK test for annual precipitation series observed at; (a) Kantale, (b) Batticaloa, (c) Pottuvil and (d)Mylambaveli of Eastern Province with a significant upward trend. 


\section{Trends in monthly rainfall data}

In the trend analysis of monthly totals, Lunuwila and Chilaw in North-western coastal line showed a significant negative trend in July with a rainfall drop of $2.0 \mathrm{~mm} /$ month and 1.6 $\mathrm{mm} /$ month respectively. Kottukachchiya and Anamaduwa in the same region showed a significant upward monthly trend for the months March $(S=130)$ and December $(S=137)$ respectively. Significant upward trends were observed at stations Kantale, Mylambaveli and Navakiri Aru in February in Eastern region. Sen's estimator of slope in these locations ranged from 3.0-5.1
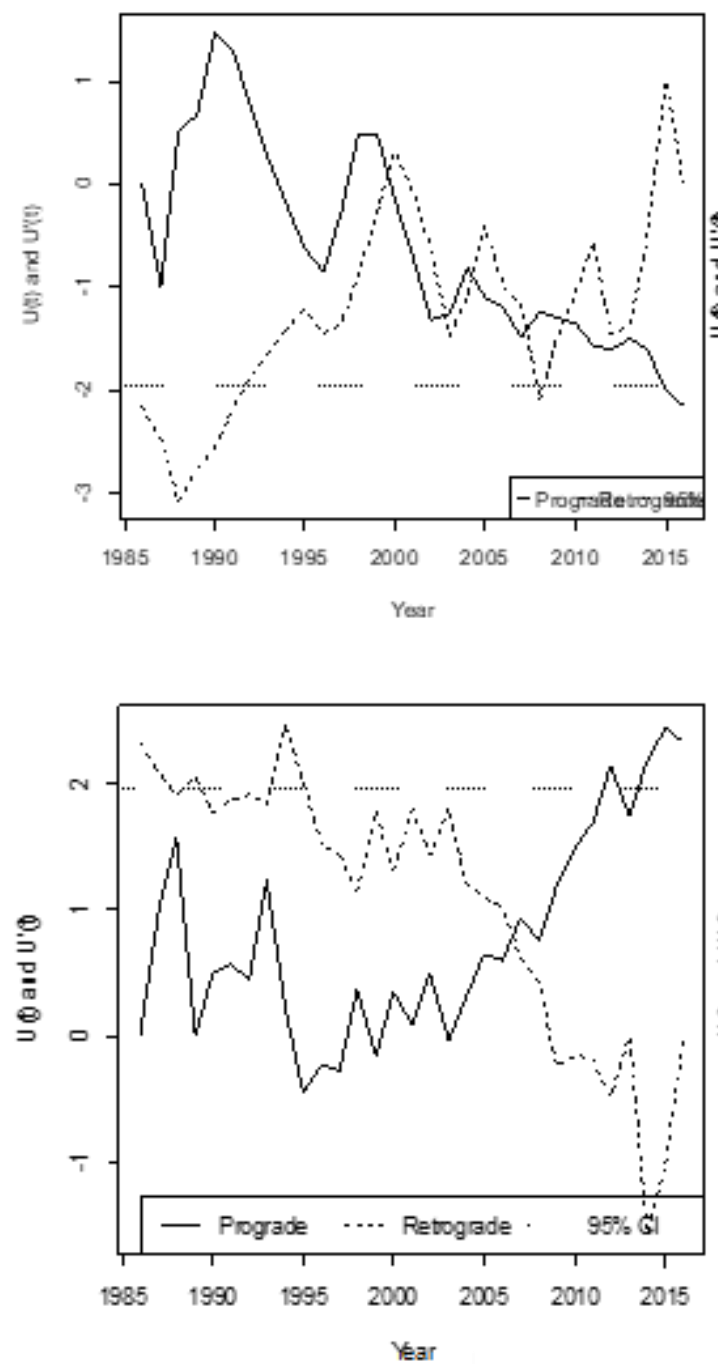

(c) $\mathrm{mm} /$ month. Contrary to this scenario, a decrease in monthly rainfall has been observed in Central India for the month of February during the period of 1901-2010 (Sanikhani et al., 2018). All other stations except Anamaduwa in North-western coastal line showed a decrease in rainfall for the month of May. The same scenario, a decrease in monthly rainfall was observed throughout the island during the month of May (Naveendrakumar et al., 2018). Such decreases in rainfall are likely due to the delay in the Southwest Monsoon seasonal wind in the region (Clift and Plumb, 2008) and this may have affected Sri Lanka.
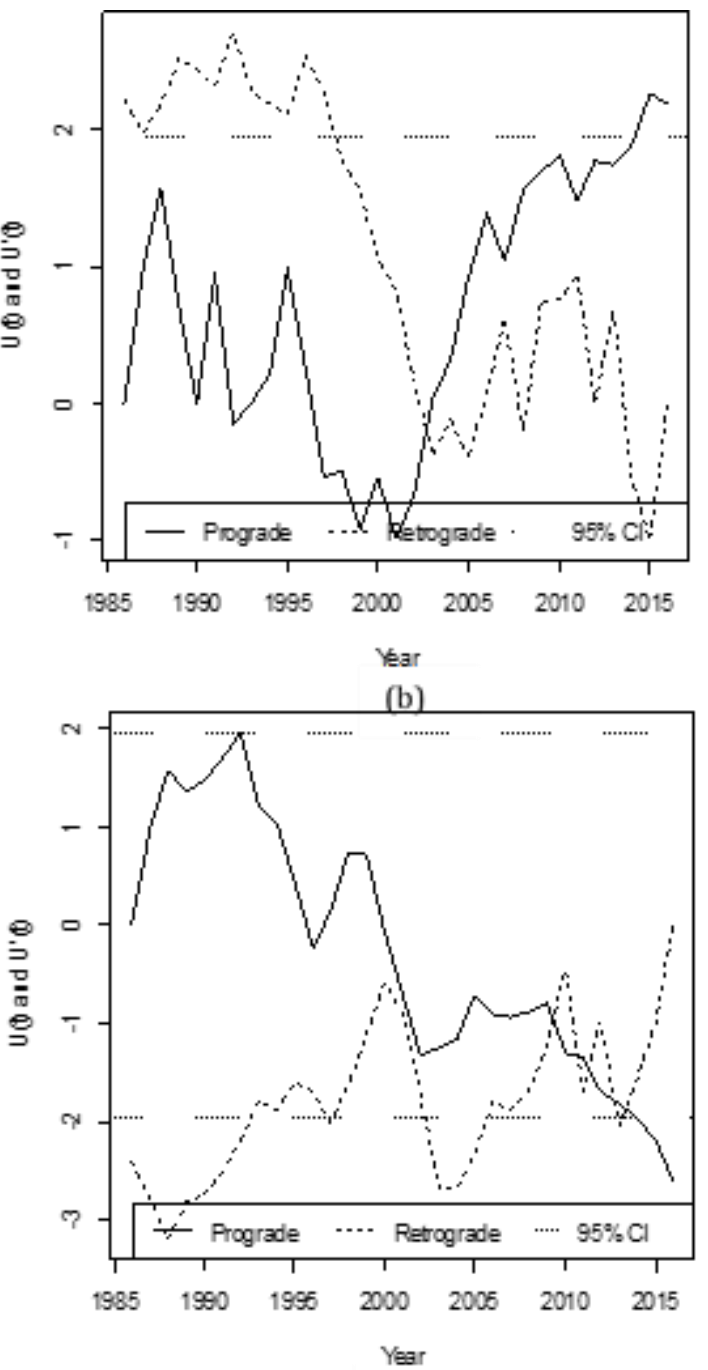

(d)

Figure 2: Graphical representation of sequential values of the statistics forward (prograde) series $u(t)$ (solid line) and backward series $u$ ' $(t)$ (dashed line) obtained by SQMK test for monthly rainfall series observed in North-western province stations at; (a) Lunuwila-July, (b) Kottukachchiya-March, (c) Anamaduwa-December and (d) Chilaw-July 
The sequential plots in the North-western coastal line (Figure 2) also clearly indicated that Lunuwila and Chilaw stations had a decreasing trend in rainfall for the month of July, while Kottukachchiya and Anamaduwa showed an increasing trend for the months March and December respectively. The prograde $u(t)$ and retrograde $u^{\prime}(t)$ series of Lunuwila (Figure 2a) show a random pattern for the considered month and has recorded an extreme rainfall event in 2016. Month of July showed a decreasing rainfall pattern for all the stations in both provinces while Lunuwila and Chilaw showed a significant trend. In Kottukachchiya, a change point was detected in 2013 for the month March, after which an increasing rainfall is observed (Figure 2b). Anamaduwa station showed a single change point in 2007 for the month of December, after which an increasing divergence is observed exceeding the 95\% confidence level. For the month of July, $u(t)$ and $u^{\prime}(t)$ plots of Chilaw

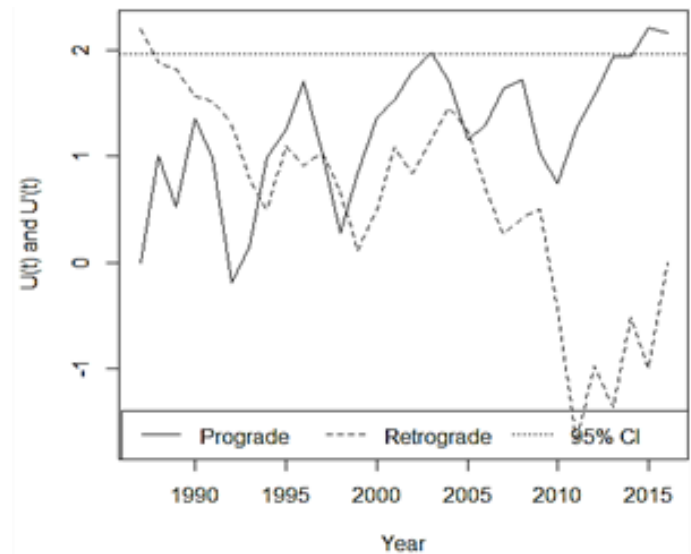

(a)

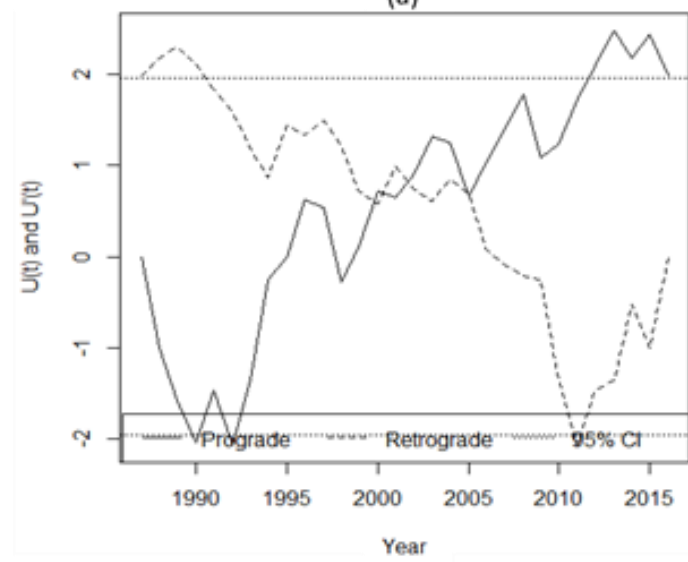

(c)
(Figure 2d) intersect each other for consecutive 5 years, since 2010. After the final intersection in 2014, the plot shows a decreasing divergence leading to extreme events in next 2 years. Month of July showed a decreasing rainfall pattern for all the stations while Lunuwila and Chilaw showed a significant trend. In India too, region-wise, the month of July has shown the highest rate of significant decreasing rainfall trend followed by August indicating rainfall decline in the monsoon months (Mondal et al., 2015).

The sequential Mann Kendall plots of monthly rainfall data in the Eastern region is given in Figure 3. The sequential plot for Kantale in February (Figure 3-a) showed five intersection points in 1994, 1997, 1999, 2005 and 2006 respectively and neither of them were significant.

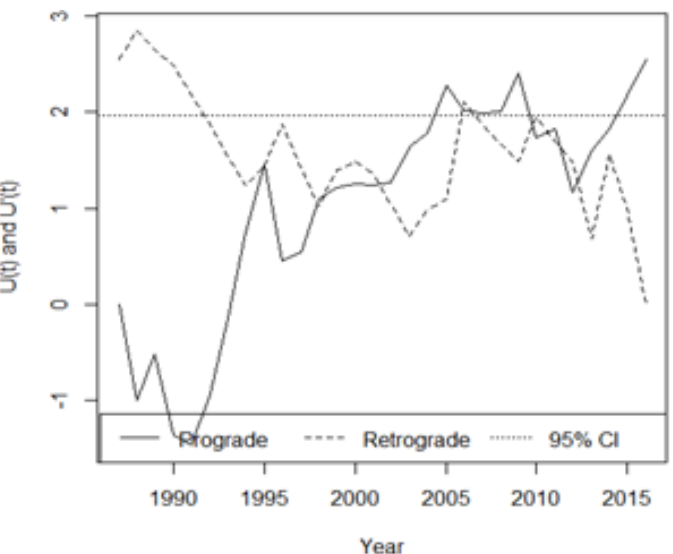

(b)

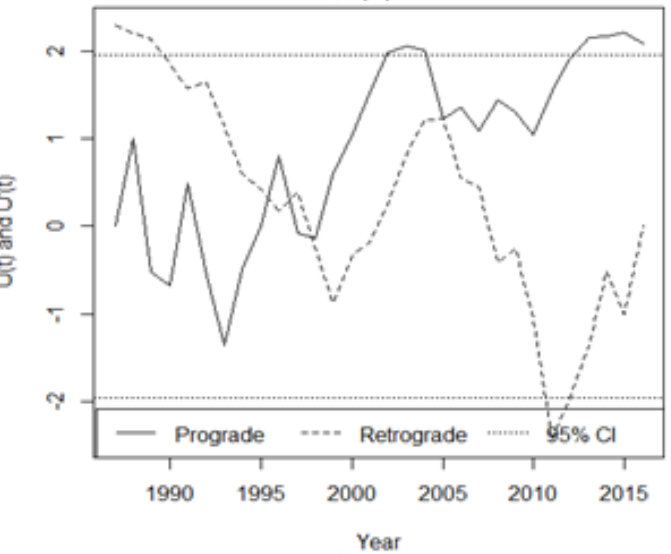

(d)

Figure 3: Graphical representation of sequential values of the statistics forward (prograde) series $u(t)$ (solid line) and backward series $u(t)$ (dashed line) obtained by SQMK test for monthly rainfall series observed in Eastern coastal line stations at; (a) KantaleFebruary, (b) Ampara-May, (c)Mylambaveli-February and (d) Navakri Aru-February 
The $\mathrm{u}(\mathrm{t})$ and $\mathrm{u}^{\prime}(\mathrm{t})$ curves of the graph exhibited an increase in rainfall over the period of study with a heavy rainfall occurrence after the last change point in 2006 for three stations Kantale, Mylambaveli and Navakri Aru (Figure 3). Sequential version of Mann-Kendall test indicated maximum number of change points in May for Ampara station and only two change points were significant (Figure $3 \mathrm{~b}$ ). The sequential plot at Mylambaveli for the month February showed an upward trend after the change point in 2006 for the considered time period (Figure 3c). The sequential Mann-Kendall plots for Navakri Aru in February is given in Figure 3d. It shows that, the $u(t)$ and $u^{\prime}(t)$ lines are converging since 1986 until they intersect each other in 2002. Again in 2005 and 2006, two consecutive intersections are seen, from where an increasing trend has started.

It is also shown in the plots (Figure 3) that during the last four years, the location has recorded extreme rainfall events exceeding the $95 \%$ confidence level. These heavy rainfall events at locations Kantale, Ampara, Mylambaveli and Navakiri Aru may be the reason behind significant increasing trends in the annual rainfall totals.

\section{Trends in seasonal data}

Our seasonal trend investigations revealed dynamic rainfall trends with both increasing and decreasing patterns in North-western and Eastern coastal line of Sri Lanka. When considering the overview of rainfall seasonal pattern in Sri Lanka, two monsoonal winds primarily influence the climate of Sri Lanka. The first, southwest monsoon (SWM), and second, northeast monsoon (NEM), which reach Sri Lanka during the months of May to September and December to February respectively (Malmgren et al., 2003). During the SWM and NEM seasons, winds come from the southwest and northeast (Wickramagamage, 2010) respectively.

During the $1^{\text {st }}$ Inter-monsoon season, the rainfall at 10 stations showed an increasing trend with no significance while Kottukachchuwa and Chilaw showed a downward trend and the rest did not record any trend. During the Southwest Monsoon season, only four of the stations, i.e. Anamaduwa of North-western region and Palampoddaru, Batticaloa, Pottuvil in Eastern region showed an increasing trend (Table 2). Interestingly, no station showed a significant upward trend for the SWM.

Out of the 15 stations showing decreasing trends for SWM, Allai tank had a significant trend with a seasonal rainfall drop of $28.6 \mathrm{~mm} /$ season. Altogether, 13 stations showed increasing rainfall trends during the second Inter-monsoon season. Among them, Kantale station had a significant upward trend. During this season, no station showed a significant decrease in the rainfall. Finally, during the Northeast Monsoon season, eight stations showed a significant upward trend (Table 2). The eight stations were Kottukachchiya and Anamaduwa of Northwestern region, and Kantale, Palampoddaru, Ampara, Batticaloa, Pottuvil andMylambaveli of the Eastern region. Among these stations Kantale, Palampoddaru, Ampara, Batticaloa, Pottuvil and Mylambaveli of the Eastern coastal line. These observations suggested a drop in rainfall during the Southwest Monsoon period while there was an increase in the rainfall during the NEM season. This overall increase in rainfall during the NEM season agrees with the results reported by Karunathilaka et al. (2017) and Naveendrakumar et al. (2018). In contrast to the decreasing rainfall, during Southwest Monsoon, an increase in the rainfall trends was observed during the two inter monsoon seasons at a majority of the stations. Similar results have been observed by Naveendrakumar et al. (2018) and in that study, during October and November, rainfall appeared to have increased at two stations in the peripheral region of Sri Lanka (Jaffna and Pottuvil), showing a statistically significant trend. According to the analysis, the decrease of rainfall in May suggested that beginning of SWM season may be delayed than its customary commencement in May, and the increase of rainfall in November may cause an earlier start of the Northeast monsoon season, instead of December. 
Table 2: Details of the Mann-Kendall trend analysis for seasonal rainfall data

\begin{tabular}{|c|c|c|c|c|c|c|c|c|}
\hline \multirow{2}{*}{ Station } & \multicolumn{2}{|c|}{$1^{\text {st }}$ Inter-monsoon } & \multicolumn{2}{|c|}{ SWM } & \multicolumn{2}{|c|}{$2^{\text {nd }}$ Inter-monsoon } & \multicolumn{2}{|c|}{ NEM } \\
\hline & $\mathbf{S}$ & $\begin{array}{l}\text { Sen's } \\
\text { slope }\end{array}$ & $\mathbf{S}$ & $\begin{array}{l}\text { Sen's } \\
\text { slope }\end{array}$ & $\mathbf{S}$ & $\begin{array}{l}\text { Sen's } \\
\text { slope }\end{array}$ & $\mathbf{S}$ & $\begin{array}{l}\text { Sen's } \\
\text { slope }\end{array}$ \\
\hline \multicolumn{9}{|c|}{ Northwestern Province } \\
\hline Puttlam & 2 & 3.8 & -19 & -20.6 & -4 & 13.6 & 16 & 27.6 \\
\hline Palaviya & 2 & 10.9 & $-30 *$ & -23.5 & -4 & -2.3 & 6 & 20.5 \\
\hline Lunuwila & 4 & -1.6 & -24 & -15.6 & -6 & -8.7 & 12 & 16.6 \\
\hline Karukkuwa & 0 & -3.4 & -26 & -17.9 & -8 & -9.5 & -8 & 7.7 \\
\hline Kottokachchiya & -8 & 2.6 & -26 & -19.0 & 4 & 3.9 & 20 & 15.7 \\
\hline Anamaduwa & 8 & 1.8 & -8 & -4.0 & 0 & 0.8 & 22 & 33.9 \\
\hline Chilaw & -13 & -5.1 & $-113^{*}$ & -51.0 & -51 & -14.3 & 54 & 7.7 \\
\hline Horakele & 8 & 4.9 & -16 & -1.2 & -2 & 12.6 & -4 & 10.8 \\
\hline \multicolumn{9}{|l|}{ Eastern Province } \\
\hline Allai tank & 6 & -3.3 & $-36^{*}$ & -28.6 & 12 & 27.1 & 26 & 92.3 \\
\hline Kallar & -2 & 1.1 & -18 & -27.1 & 16 & 36.4 & 18 & 60.0 \\
\hline Kantale & 23 & 20.4 & -14 & -5.3 & $36^{*}$ & 69.1 & $28^{*}$ & 85.3 \\
\hline Palampoddaru & 2 & 9.1 & -10 & -9.7 & 20 & 55.6 & 22 & 93.0 \\
\hline Ampara & $28^{*}$ & 22.5 & -20 & 0.5 & 18 & 17.9 & 20 & 79.7 \\
\hline Batticaloa & 6 & 14.5 & -4 & -2.7 & 18 & 26.2 & $28^{*}$ & 77.4 \\
\hline Trincomalee & 24 & 13.6 & $-32^{*}$ & -33.6 & 18 & 24.2 & 18 & 39.6 \\
\hline Pottuvil & 0 & 6.5 & -10 & -2.9 & 2 & 1.5 & $32^{*}$ & 96.1 \\
\hline Mylambaveli & 0 & -2.5 & -19 & -8.8 & 6 & 13.9 & $30^{*}$ & 74.9 \\
\hline Navakiri Aru & 19 & 14.8 & -24 & -22.1 & -10 & -40.2 & 22 & 69.2 \\
\hline Sagamam Kulam & -70 & -17.3 & -42 & 0.1 & 59 & 7.1 & 42 & 39.8 \\
\hline
\end{tabular}

*statistically significant at (P-value $\leq 0.05)$

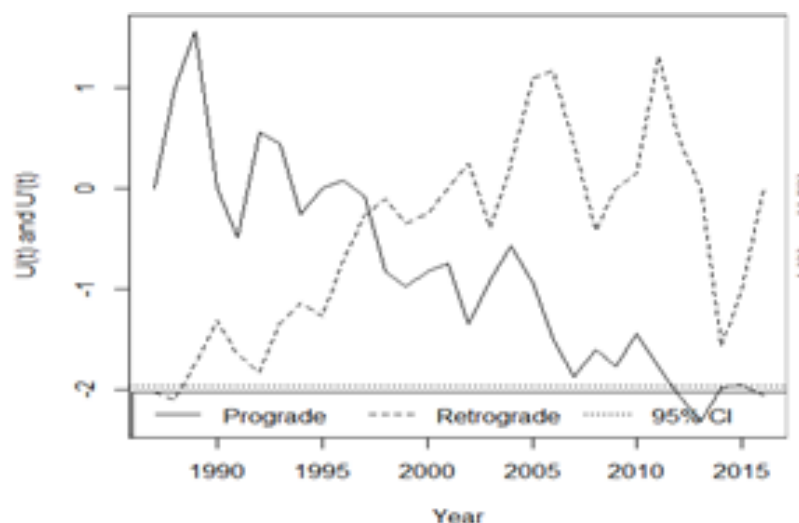

(a)

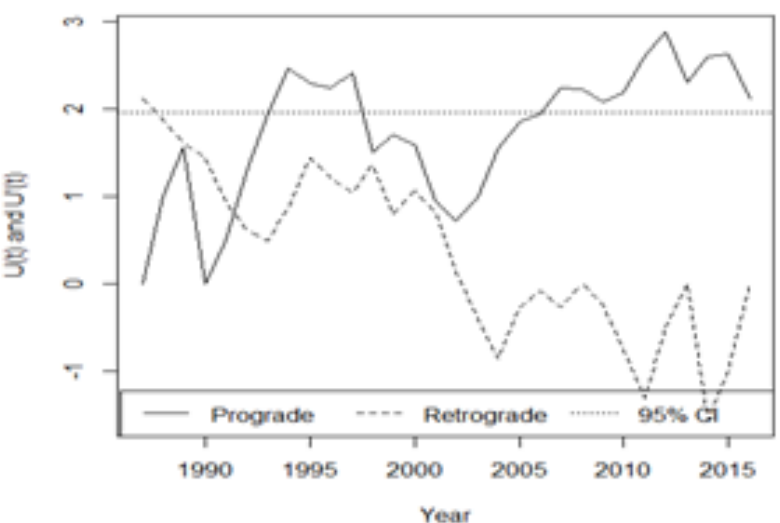

(b)

Figure 4: Graphical representation of seasonal sequential values of the statistics prograde series $u(t)$ (solid line) and backward series $u^{\prime}(t)$ (dashed line) obtained by SQ-MK test for seasonal precipitation observed at; (a) Allai tank-SWM season (b) Kantale- $2^{\text {nd }}$ Intermonsoon season. 
The Sequential graphs of Allai tank showed a significant decreasing trend with one change point in 1998 for SWM season, and Kantale showed a significant trend for the second Inter-monsoon season with a change point in

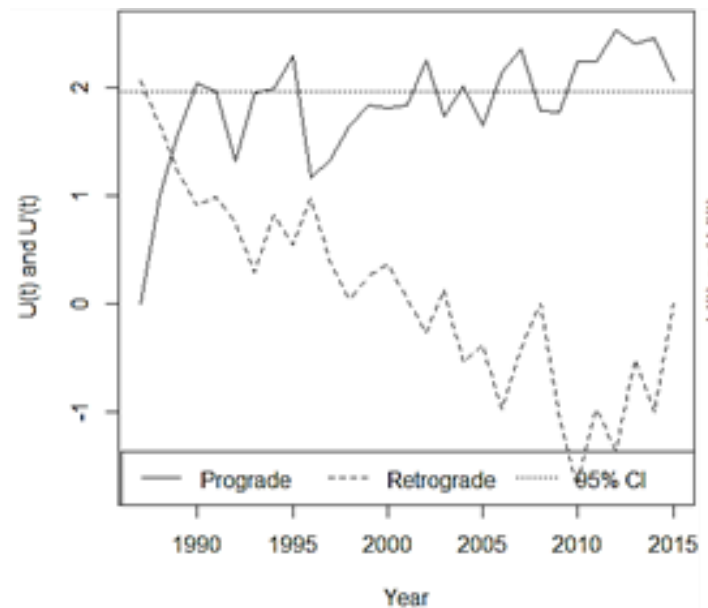

(a)
1993 (Figure 4). The Sequential graphs of stations with significant trends (Kantale, Batticaloa, Pottuvil and Mylambaveli) showed a random pattern for NEM except for two stations Pottuvil and Mylambaveli (Figure 5).

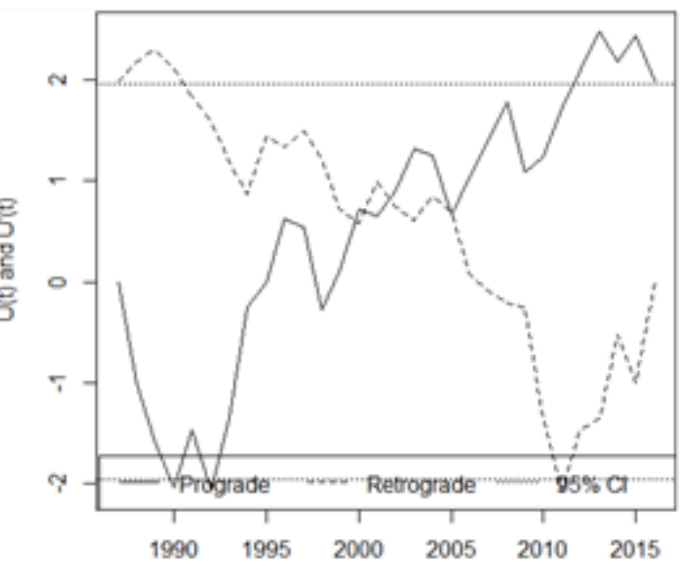

(b)

Figure 5: Graphical representation of seasonal sequential values of the statistics prograde series $u(t)$ (solid line) and backward series $u(t)$ (dashed line) obtained by SQ-MK test for NEM seasonal precipitation series observed at; (a) Potuvil (b) Mylambaveli

Rainfall is an essential climatic parameter, which directly affects agriculture, aquaculture and water resource availability. From the present study, it was observed that most of the considered stations in the North-western and Eastern coasts have location specific trends. Changes in seasonal trends delay the cropping season and hence needs modification of the current crop calendars in some stations. Changes in climate variables may largely affect the shrimp yield by increasing frequency of shrimp disease, causing physical damage to farm structure and deteriorating quality of water. Shrimp farmers can try to adapt to those changes in various ways, including increasing pond depth, exchanging tidal water, strengthening earthen dikes, and netting and fencing around the dikes along with changes in the culture calendar. Therefore, changes in rainfall should be carefully taken into consideration to assess impacts and implement mitigating strategies for industries in the considered areas.

\section{CONCLUSIONS}

The annual, monthly and seasonal trend investigations revealed dynamic rainfall trends with both increasing and decreasing patterns in the North-western and Eastern coasts of Sri Lanka. Results indicated a significant upward trend in annual total rainfall at Kantale, Batticaloa, Pottuvil and Mylambaveli in the Eastern province. Trends in monthly totals were significant in February for the stations Kantale, Mylambaveli and Navakri Aru in Eastern coastal line. Two significant downward trends were recorded at Lunuwila and Chilaw for the month of July in North-western. Despite these varying trends in general, a downward trend at all 19 stations were observed during Southwest monsoon. One location, Allai tank on Eastern region showed a significant downward trend for this season. Trends in Northeast monsoon was significant in four stations in the Eastern province and two stations in the Northwestern Province showing an increase in seasonal total rainfall. The Sequential MannKendall plots of the Northeast monsoon showed extreme rainfall events for this province. The study concludes that climate change in terms of rainfall is location specific, and hence, locational analysis is essential for assessing the impact and implementing proper mitigation strategies. 


\section{REFERENCES}

Abdi, A., Hassanzadeh, Y., Talatahari, S., Fakheri-Fard, A. and Mirabbasi, R. (2017). Regional drought frequency analysis using Lmoments and adjusted charged system search. Journal of Hydroinformatics, 19: 426-442. https://doi.org/10.2166/hydro.2016.228

Ahmadi, F., Nazeri Tahroudi, M., Mirabbasi, R., Khalili, K. and Jhajharia, D. (2018). Spatiotemporal trend and abrupt change analysis of temperature in Meteorological Applications. $\quad 25:$ 314-321. https://doi.org/10.1002/met.1694

Ampitiyawatta, A. and Guo, S. (2010). Precipitation trends in the Kalu Ganga basin in Sri Lanka Journal of Agricultural Sciences. https://doi.org/10.4038/jas.v4i1.1641

Bhuyan, M.D.I., Islam, M.M. and Bhuiyan, M.E.K. (2018). A Trend Analysis of Temperature and Rainfall to Predict Climate Change for North-western Region of Bangladesh. American Journal of Climate Change, 07: 115-134. https://doi.org/10. 4236 /ajcc.2018.72009

Birsan, M., Molnar, P., Burlando, P. and Pfaundler, M. (2005). Streamflow trends in Switzerland. Journal of Hydrology, 314: 312329.

Burn, D.H. and Elnur, M.AH. (2002). Detection of hydrological trends and variability. Journal of Hydrology, 255: 107-122.

Chiew, F.H.S. and McMahon, T.A. (1993). Detection of trend or change in annual flow of Australian rivers. International Journal of Climatology, 13: 643-653.

Burt, T. and Weerasinghe, K. (2014). Rainfall Distributions in Sri Lanka in Time and Space: An Analysis Based on Daily Rainfall Data. Climate, 2: 242-263. https://doi.org/10. $3390 /$ cli2040242

Cannarozzo, M., Noto, L. V. and Viola, F. (2006). Spatial distribution of rainfall trends in Sicily (1921-2000). Physics and Chemistry of the Earth, 31: 1201-1211. https://doi.org/10.1016/j.pce.2006.03.022

Chowdhury, R.K., Beecham, S., Boland, J. and Piantadosi, J. (2015). Understanding South
Australian rainfall trends and step changes. International Journal of Climatology. 35, 348360. https://doi.org/10.1002/joc.3982

Clift, Peter and Plumb, R. (2008). The Asian monsoon: Causes, history and effects. DOI:10.1017/CBO9780511535833.

Da Silva, V.D.P.R. (2004). On climate variability in Northeast of Brazil. Journal of Arid Environments,

https://doi.org/10.1016/j.jaridenv.2003.12.0 02

De Costa, W.A.J.M. (2010). Adaptation of agricultural crop production to climate change: A policy framework for Sri Lanka. Journal of the National Science Foundation of Sri Lanka. https://doi.org/10.4038 /jnsfsr .v38i2.2032

González, J.M., Ontiveros, V.G. and De Jesús Návar Cháidez, J. (2008). Analysis of rainfall trends (1920-2004) in Mexico. Investigaciones Geograficas. 65: 38-55. Hamed, K.H. (2008). Trend detection in hydrologic data: the Mann-Kendall trend test under the scaling hypothesis. Journal of hydrology, 349(3-4): 350-363.

Hamed, K. (2008). Trend Detection in Hydrologic Data: The Mann-Kendall Trend Test Under the Scaling Hypothesis. Journal of Hydrology. 349: 350-363. https://doi.org/10. 1016/j.jhydrol.2007.11.009.

Hirsch, R.M., Slack, J.R. and Smith, R.A. (1982). Techniques of Trend Analysis for Monthly Water Quality Data. Water Resources Research, 18(1): 107-121.

Jayawardene, H., Sonnadara, D. and Jayewardene, D. (2005). Trends of Rainfall in Sri Lanka over the Last Century. Sri Lankan Journal of Physics, https://doi.org/10. 4038/sljp.v6i0.197

Jayawardene, H.K.W.I., Jayewardene, D.R. and Sonnadara, D.U.J. (2015). Interannual variability of precipitation in Sri Lanka. Journal of the National Science Foundation of Sri Lanka, 6:7-17. https://doi.org/10.4038/jnsfsr.v43i1.7917

Karunathilaka, K.L.A.A., Dabare, H.K. V. and Nandalal, K.D.W. (2017). Changes in Rainfall in Sri Lanka during 1966 - 2015. Engineer: 
Journal of the Institution of Engineers, Sri Lanka, 50: 39-48.

Kendall M.G. (1975). Rank correlation measures. Charles Griffin, London.

Khaniya, B., Jayanayaka, I., Jayasanka, P. and Rathnayake, U. (2019). Rainfall Trend Analysis in Uma Oya Basin, Sri Lanka, and Future Water Scarcity Problems in Perspective of Climate Variability. Advances in Meteorology, 1-10. https://doi.org/10.1155/2019/3636158

Kumar, S., Merwade, V., Kam, J. and Thurner, K. (2009). Streamflow trends in Indiana: Effects of long term persistence, precipitation and subsurface drains. Journal of Hydrology, 374, 171-183. https://doi.org/10.1016/ j.jhydrol.2009.06.012

Makokha, G.L. and Shisanya, C.A. (2010). Trends in Mean Annual Minimum and Maximum Near Surface Temperature in Nairobi City, Kenya. Advances in Meteorology, 1-6. https://doi.org/10.1155/2010/676041

Malmgren, B.A., Hulugalla, R., Hayashi, Y. and Mikami, T. (2003). Precipitatioon trends in Sri Lanka since the 1870s and relationships to El Niño-southern oscillation. International Journal of Climatology, 23(10): 1235-1252. https://doi.org/10.1002/joc.921

Mann H.B. (1945). Nonparametric test against trend. Econometrica, 13:245-259.

Mondal, A., Khare, D. and Kundu, S. (2015). Spatial and temporal analysis of rainfall and temperature trend of India. Theoretical and Applied Climatology, 122: 143-158. https://doi.org/10.1007/s00704-014-1283-z

Munasinghe, M.N., Stephen, C., Abeynayake, P. and Abeygunawardena, I.S. (2010). Shrimp farming practices in the Puttallam district of Sri Lanka: Implications for disease control, industry sustainability, and rural development. Veterinary Medicine International, 1-6. https://doi.org/10. $4061 / 2010 / 679130$

Muralidhar, M., Kumaran, M., Jayanthi, M., Muniyandi, B. and Ponniah, A.G. (2012). Case study on the impacts of climate change on shrimp farming and developing adaptation measures for small-scale shrimp farmers in Krishna District, Andhra Pradesh, India Case
Study Report. Available at https://enaca.org/enclosure.php?id=441

Naveendrakumar, G., Vithanage, M., Kwon, H.H., Iqbal, M.C.M., Pathmarajah, S. and Obeysekera, J. (2018). Five decadal trends in averages and extremes of rainfall and temperature in Sri Lanka. Advances in Meteorology, 13pp. https://doi.org/10. $1155 / 2018 / 4217917$

Partal, T. and Kahya, E. (2006). Trend analysis in Turkish precipitation data. Hydrological Processes, 20: 2011-2026.

Rahman, M.A., Yunsheng, L. and Sultana, N. (2017). Analysis and prediction of rainfall trends over Bangladesh using Mann-Kendall, Spearman's rho tests and ARIMA model. Meteorology and Atmospheric Physics. 129: 409-424. https://doi.org/10.1007/s00703016-0479-4

Ranatunge, E., Malmgren, B.A., Hayashi, Y., Mikami, T., Morishima, W., Yokozawa, M. and Nishimori, M. (2003). Changes in the Southwest Monsoon mean daily rainfall intensity in Sri Lanka: Relationship to the El Niño-Southern Oscillation. Palaeogeography, Palaeoclimatology, Palaeoecology. 197(12):1-14. https://doi.org/10.1016/S00310182(03)00383-3

Ratnayake, U. and Herath, S. (2005). Changing rainfall and its impact on landslides in Sri Lanka. Journal of Mountain Science. 2: 218224. https://doi.org/10.1007/bf02973195

Rimi, R.H., Farzana, S., Sheikh, M.S., Abedin, M.Z. and Bhowmick, A.C. (2013). Climate Change Impacts on Shrimp Production at the South-West Coastal Region of Bangladesh. World Environment. 3(3): 116-125. https://doi.org/10.5923/j.env.20130303.07

Sen, P.K. (1968). Journal of the American Statistical Estimates of the Regression Coefficient Based on Kendall's Tau. Journal of American Statistic Association. 63: 13791389.

Sneyres, R. (1990). Technical note no. 143 on the statistical Analysis of Time Series of Observation, World Meteorological Organisation (WMO), Geneva: 192. 
Solomon, S. (2007). Fourth assessment report of the Intergovernmental Panel on Climate Change: the physical science basis. Cambridge University Press, 93pp.

Sukrutha, A., Dyuthi, S.R. and Desai, S. (2017). Multimodel Response Assessment for Monthly Rainfall Distribution in Some Selected Indian Cities Using Best Fit Probability as a Tool. Applied Water Science. 1-10. https://doi.org/10.1007/s13201-018-0789-4

Tabari, H. and Marofi, S. (2010). Changes of Pan Evaporation in the West of Iran. Water Resources Management. 25: 97-111. https://doi.org/10.1007/s11269-010-9689-6

Warnasooriya, P.G.A.S, Peiris, T.U.S., Wijeratne, A.W. and Jayasinghe, J.M.P.K. (2018). Climate change and its impact on shrimp production: farmers' perception in North-western province in Sri Lanka. In: WinC 2018. [online] Wayamba University, Kuliyapitiya: p.363. Available at http://winc.wyb.ac.lk/Resours/Eversion_Win C_2018.pdf [Accessed 19 Jul. 2019].

Wickramagamage, P. (2016). Spatial and temporal variation of rainfall trends of Sri Lanka. Theoretical and Applied Climatology. https://doi.org/10.1007/s00704-015-1492-0

Xu, Z.X., Li, J.Y. and Liu, C.M. (2007). Long-term trend analysis for major climate variables in the Yellow River basin. Hydrological
Processes.

21:1935-1948. https://doi.org/10.1002/hyp.6405

Yue, S., Pilon, P., Phinney, B. and Cavadias, G. (2002). The influence of autocorrelation on the ability to detect trend in hydrological series. Hydrological Processes, 16: 18071829. https://doi.org/10.1002/hyp.1095

Yue, S. and Wang, C.Y. (2004). The MannKendall test modified by effective sample size to detect trend in serially correlated hydrological series. Water Resources Management. 18: 201-218. https://doi.org/10.1023/B:WARM.00000431 40.61082 .60

Zamani, R., Mirabbasi, R., Nazeri, M., Meshram, S.G. and Ahmadi, F. (2018). Spatio-temporal analysis of daily, seasonal and annual precipitation concentration in Jharkhand state, India. Stochastic Environmental Research and Risk Assessment., 32: 10851097. https://doi.org/10.1007/s00477-0171447-3

Zubair, L., Hansen, J., Chandimala, J., Siraj, M., Siriwardhana, M., Tennakoon, U., Yahiya, Z., Ariyaratne, K., Bandara, I., Bulathsinhala, H., Rajakaruna, S.B., Abeyratne, T. and Samuel, T.D.M.A. (2005). Current climate and climate change assessments for coconut and tea plantations in Sri Lanka. Available at http://tropicalclimate.org/mdp/resourcesfor mdp/plantation_Edit15_R.pdf 